\title{
Chalmers' Refutation of Materialists Concept of Consciousness
}

\author{
Dr. Shanjendu Nath \\ Associate Professor, Rabindrasadan Girls' College, Karimganj, Assam, India.
}

\begin{abstract}
It is undoubtedly true that the phenomenon of consciousness is familiar to us and cannot be denied. In our waking lives at every moment we are conscious of something or other. But the problem is- what is consciousness? Can it be known? Attempts have been made to explain the nature of it by different philosophers in different times but yet none can give us a satisfactory and well accepted solution of the problem. But yet effort is not stopped. Materialists believe that there is nothing over and above matter and thereby they opine that consciousness is a process in the brain. Thus in this article I shall try to highlight a brief outlines of the materialist concept of consciousness, particularly the views of U. T. Place and Armstrong and finally explore Chalmers' arguments against materialism.
\end{abstract}

Key Words: proprioception, supervenience, zombie, consciousness, metaphysical.

\section{Introduction}

It is true that in recent times much progress has been made in the science of mind. For a better understanding of the human behaviour and of the processes that produce it, the recent work in cognitive science and neuroscience is leading us. In theories of cognition we do not have perfection but it is sure that the details are not too far from our reach. Yet consciousness is a matter of puzzle. That the causation of behaviour should be accompanied by a subjective inner life is still utterly mysterious. The view that the physical system, such as, brain is the cause of consciousness is believed by us as because we have good reason in favour of such a belief. But to answer the question of how it arises, or why it exists at all, we have little idea. Brain is a physical system but how this physical system is also a system of an experience at the same time is undoubtedly a genuine and complex question. Thus the question about consciousness is really a difficult one and this difficult question is hardly touched by the recent scientific theories. In order to answer the question how consciousness fits into the natural order, it cannot just be said that we have no detailed theory about it. It is rather that we are entirely in the dark about consciousness.

In the past few years many philosophers have written different books and articles on consciousness and might claim that they have made progress in answering the problem of consciousness. But if one looks into the matter closer then he will find that the claimer has not touched the hardest problem of consciousness. They either knowingly or unknowingly ignored the central problem of consciousness. Thus the problem of consciousness has remained a puzzling one forever. But this does not mean that it is a matter of despair. Rather this puzzlement makes the problem of consciousness an exciting challenge to the intellectuals at present time. It is because of the fact that this problem is a fundamental one and at the same time ill understood. Our conception of the universe and of ourselves is profoundly affected by a solution of the problem.

Some people are of the opinion that consciousness is an illusion. But this opinion cannot be accepted as because among all other things that we find in this universe, consciousness has the surer existence, although its existence cannot be proved. Its existence is understood directly.

\section{Materialists' Concept Of Consciousness}

Materialist thinker U. T. Place says that consciousness is a process in the brain. When he claims that 'consciousness is a process in the brain' he asserts that this statement is neither necessarily true nor necessarily false. This statement, according to him, is neither self-evident nor self-contradictory. In this connection Place cited an analogy to convince us that his position is correct. He says that as the statement "Lightning is a motion of electric charges" is a reasonable scientific hypothesis so is the statement "consciousness is a process in the brain". He cited potential explanatory power as the reason for hypothesizing consciousness-brain state relations in terms of identity rather than mere correlation.

In explaining the notion of consciousness Armstrong says, "Consciousness, or experience, then (as opposed to completely unselfconscious mental activity which is perfectly possible, and which occurs in the case of the 'automatic driving') is simply awareness of our own state of mind. The technical term for such awareness of our mental state is 'introspection' or introspective awareness." 
While debating with Norman Malcolm, Armstrong compared consciousness with proprioception. In explaining the nature of proprioception he exemplifies that when our eyes are not open and without touch we are immediately aware of the angle at which one of our elbows is bent, a case of proprioception occurs. Different from that of bodily sensation, proprioception is a special sense by which we become aware of the parts of our body. We also become aware of the states and processes of our brain through proprioception. Armstrong makes a distinction between proprioception and mere awareness. As distinguished from mere awareness, the proprioception is higher order awareness. Here one part of brain is perceived by the brain itself. He anticipates that some may see regress here that is, there can be proprioception of proprioception, proprioception of proprioception of proprioception and so on. But he believes that this sequence will not probably go up more than two or three steps. In this sequence, the last proprioception will not be propriocepted. This may help to explain our sense of the ineffability of consciousness.

\section{Chalmers' Arguments}

Chalmers points out that consciousness cannot be defined. What can be said about consciousness is its clarification. Thus he says that in the most interesting sense, experience is central to consciousness. It is fruitless to define consciousness in terms of more primitive notions. Thus he openly admits that 'consciousness' refers to a number of phenomena and thus this term is ambiguous. But he categorically states that when he talks about consciousness, he talks by the term only about the subjective quality of experience.

In developing the account of consciousness Chalmers accepted a number of constraints. Among these constraints the first and most important one he mentions is that to take consciousness seriously. In developing a theory of consciousness the easiest way, according to him, is to deny its existence or it is better to say that the phenomena which are needed for explaining what it is not must be redefined. But this approach does not really solve the problem; rather the strategy escapes the problem. In his book 'The Conscious Mind' Chalmers assumed that consciousness exists. But it is unacceptable to him to redefine the problem by explaining how certain cognitive or behavioural functions are performed.

Chalmers believes that consciousness is a problem no doubt and this problem lies at the border of science and philosophy. He further emphatically stated that the problem of consciousness is properly a subject matter of science. Like motion, life, and cognition, it is a natural phenomenon and the explanation of consciousness is possible in the way that these are done. But it is also true that by the usual scientific methods consciousness cannot be investigated. In observing the phenomenon of consciousness, it is difficult on the part of scientific method to have grip over it. The collection of data of consciousness is very hard outside the first person case. But this does not mean that there is no relevance of external data. Before justifying the relevancy of external data we will have to arrive first at a coherent philosophical understanding. Thus Chalmers' conclusion regarding the problem of consciousness is that, may be it a scientific problem but it requires philosophical methods of understanding.

Chalmers has given arguments for rejecting a materialistic account of consciousness. He holds that materialism cannot explain how consciousness could amount to physical structure and processes. He argues that if one takes consciousness seriously, he should endorse dualistic theory like the property dualism. In the philosophical study of consciousness there are mainly three schools of thought. Viz., (a) dualism with its forms, (b) materialism, and (c) eliminativism. Among these three schools of thought, the study of consciousness is the most controversial issue and Chalmers provides a good guide to the important issue. He also claims that eliminativism does not take consciousness seriously, so he argues against this theory. Thus in this paper I shall try to explore Chalmers' view of consciousness against materialism.

What is consciousness? Some philosophers often referred to consciousness as what it is like to feel pain or to see the colour red. There are different terms used by philosophers, such as, 'qualia', 'phenomenal feel', and 'the subjective quality of experience' and all of these terms make reference to consciousness. There are grammatical differences among these terms but apart from these there are mostly subtle differences among these which are known as a matter of connotation. Thus Chalmers says that 'to have qualia', 'to have subjective experience' and so on are roughly synonymous with 'to be conscious'. He has mentioned a catalogue of conscious experiences. These are - visual experiences, auditory experiences, tactile experiences, olfactory experiences, taste experiences, experience of hot and cold, pain, other bodily sensations, mental imagery, conscious thought, emotions and sense of self.

After mentioning the different types of conscious experiences Chalmers also mentions that this catalogue covers only a number of cases and it leaves out some other important experiences which he does not mention in this list. Dreams, arousal and fatigue, intoxication or the novel character of other drug-induced experiences may also be included in the list of conscious experiences. He also mentions that from the combination of two or many of the components as mentioned above, there are also rich experiences. In the list of conscious experiences given above he only mentions the combined effects of smell and taste. But in addition to these, there are other combined experiences such as, music and emotion which are difficult to separate 
because they interact in a subtle manner. He also mentions that another important thing that he left aside is the unity of conscious experiences which is experienced by a single experiencer. This kind of experience is very difficult to pin down as because it is very much different from any other specific experiences. Due to its complexity sometimes it seems to be illusory. But Chalmers believes that there is a strong intuition behind this unity of experience.

Chalmers holds that it is not correct to say that mind is full of wholly conscious experiences. In this connection he refers that modern cognitive science says so much about mind in general but it says nothing about consciousness. This cognitive science deals with the explanation of behaviour and it believes that the internal basis of behaviour is mind. It also believes certain mental states which are relevant to the causation and explanation of behaviour. But it cannot be certainly stated that these internal mental state, which are responsible for the causation and explanation of behaviour is conscious or not.

He further says that there are two distinct concepts of mind which lie at the very root of this analysis. Of these two concepts the first one is phenomenal and the second is psychological. All conscious experiences or consciously experienced mental states are phenomenal. The psychological concept is the causal or explanatory basis of behaviour. Thus whether a mental state has a conscious quality or not is less important for psychological concept of mind. But Chalmers believes that these two concepts of mind are intimately related. $\mathrm{He}$ also believes that mental is exhausted by these two concepts of mind and that is why he declares that all mental properties must be either phenomenal or psychological or both. Even intentional states, emotional states and others can be assimilated in any of them or to both.

There are different ways through which the problem of consciousness can be viewed. One of them is to think of it as the old mind-body problem with a new set of concepts to consider. In recent times one of the most important debates about consciousness is that of supervenience. The concept of supervenience can be understood as dependence relation between two sets of properties. Suppose there are two levels of properties, a set of higher level properties and a set of lower level properties and if the higher level properties depend upon the lower level properties then the set of higher level properties supervenes on a set of lower level properties. This supervenience is defined by Chalmers as

"B-properties supervene on A-properties if no two possible situations are identical with respect to their A-properties while differing in their B-properties."

The purpose of the notion of Supervenience is to have understanding of higher level properties of organism, such as, size, shape and behaviour which really depend upon and can be explained by much lower level properties, such as, genes, DNA, nerve impulses etc. Supervenience can be of several types- logical, metaphysical and natural supervenience. These concepts can help us to understand the argument put forwarded by the materialists, property dualists and eliminativists. Chalmers characterizes logical supervenience as follows,

"B-properties supervene logically on A-properties if no two logically possible situations are identical with respect to their A-properties but distinct with respect to their B-properties." ${ }^{3}$

But Chalmers believes that beside logical supervenience there can be other supervenience. He describes natural supervenience as the result of two sets of properties being found in the natural world but systematically and perfectly correlated. The concept of natural supervenience is formally stated as: B-properties supervene naturally on A-properties if any time two situations which could naturally arise in our world share the same Aproperties; they also share the same B-properties. The natural laws in our world such as, the laws of physics, upon which depends the question- whether some properties naturally supervenes on another property or not. It is empirical possibility and impossibility by which natural supervenence has to be understood. Natural Supervenience is there where two properties are related by causally necessity in our natural world, not in all possible worlds. The ideal gas law is an example of naturally necessary phenomena which is not logically necessary. If it happens that B-properties naturally supervene on A-properties, then it is conceivable that without the same A-properties the same B-properties could be instantiated. It would break the laws of physics if it ever happens in our world.

So far I have discussed the logical supervenience and natural supervenience. Now I shall discuss metaphysical supervenience. Metaphysical supervenience is not based on either logical or natural necessity but on metaphysical necessity. This type of identity is credited to Saul Kripke. He makes a distinction between logical identity and metaphysical identity. Logically two things are identical if it is impossible that they could be distinct things and the identity is due to the meanings of the terms. But metaphysical identity depends upon how our world turns out. The identity of water and $\mathrm{H}_{2} \mathrm{O}$ is the classic example of metaphysical identity. Kripke's argument that, once we discover the chemical composition of $\mathrm{H}_{2} \mathrm{O}$ is water in our world, it will be same thing in all possible worlds. We may imagine that the stuff we find in lakes and oceans, that is water, might not have had 
the chemical composition $\mathrm{H}_{2} \mathrm{O}$. But once the identity of water and $\mathrm{H}_{2} \mathrm{O}$ is discovered a posteriori, metaphysically water is identical to $\mathrm{H}_{2} \mathrm{O}$.

The metaphysically supervenience can be formally exemplified as B-properties supervene metaphysically on A-properties if it is metaphysically impossible for two situations or objects to have exactly the same B-properties without having the same A-properties.

Thus it is some form of metaphysical identity or metaphysical supervenience on which the materialists often appeal in order to find out a way to overcome the recent debate on consciousness and to hold materialism. But Chalmers firmly believes that materialism cannot be saved by the notion of metaphysical identity. His view is that the problem which he raises with the logical supervenience cannot be avoided by the materialist on the appeal to metaphysical supervenience. Hence, the materialism must hold that consciousness is logically supervenient on the physical and therefore, materialism fails to solve the problem of consciousness.

In order to reject materialism Chalmers puts forward arguments against the logical supervenience of consciousness. His first argument stems from the logical possibility of "zombies". In the philosophical literature a 'zombie' is supposed to be a person-like being in all respects having language ability, appearance, behaviours, possession of beliefs and desires. But in spite of all these similarities, it lacks consciousness. Chalmers himself imagines his zombie twin who lives on a twin earth and who is physically identical to him. He also believes that the physical environment of this twin earth is identical with our own. The zombie twin that he imagines also looks and acts just like real Chalmers does in our real world. But the twin Chalmers lacks all kinds of phenomenal experiences that one being experienced by the real Chalmers.

Chalmers by his imaginative argument tries to show that zombies are logically possible creatures and this logical possibility of zombies proves that materialism is false. Thus by the following points his argument can be summarized.

1. It is an empirical claim that in our world consciousness exists.

2. Because zombies are logically possible, consciousness cannot logically supervene on the physical.

3. Therefore, just by appeal to physical facts one cannot explain the occurrence of consciousness.

It is the contention of Chalmers that materialism is committed to the view that consciousness is logically supervenient on the physical and therefore materialism is false.

Thus after refutation of materialist viewpoint of consciousness Chalmers put forwarded his own opinion about it. He says:

"That consciousness is a natural phenomenon seems hard to dispute: it is an extraordinary salient part of nature, arising throughout the human species and very likely in many others. And we have every reason to believe that natural phenomena are subject to fundamental natural laws; it would be very strange if consciousness were not. This is not to say that the natural laws concerning consciousness will be just like laws in other domains, or even that they will be physical laws. They may be quite different in kind." ${ }^{4}$

\section{Conclusion}

From the above analysis it is clear that materialists attempt to explain consciousness with the help of matter and thereby they do not believe the existence of anything over and above brain processes. But Chalmers rejected the materialist' argument on different grounds. He did so only with the intention to establish his dualistic theory of consciousness. But whatever may by argued against materialist concept of consciousness it is true that the position of materialism is most plausible in explaining the problem of consciousness.

[1]. Armstrong. D.M., Bodily Sensations, London, Routledge,1961.

[2]. Armstrong. D.M., 'Consciousness and Causality', and 'Reply'. In Armstrong, D.M. and Malcolm. N., Consciousness and Causality, Oxford, Blackwell, 1962.

[3]. Armstrong. D.M., A Materialist Theory of the Mind, London, Routledge. Second Edition with new preface 1993, (1968a).

[4]. Armstrong. D.M., Martin, C.B. and Place, U.T., Dispositions: A Debate, T. Crane (ed.), London, Routledge, 1996.

[5]. $\quad$ Armstrong. D.M., Perception and the Physical World, London, Routledge, 1961.

[6]. Beakley. B. and Ludlow. P. (ed), The Philosophy of Mind, Classical Problems/ Contemporary Issues, New Delhi, 2007.

[7]. Chalmers. D.M., The Conscious Mind, New York, Oxford University Press, 1996.

[8]. Chalmers. D.M., Philosophy of Mind: Classical and contemporary Readings, Oxford University Press, USA, 2002.

[9]. Dennett. D.C., Consciousness Explained, Boston, Little and Brown, 1991.

[10]. Hill. C.S., Sensations: A Defense of Type Materialism, Cambridge, Cambridge University Press, 1991.

[11]. Kim. J., Philosophy of Mind, Westview Press, 2006.

[12]. Lycan. W.G., Consciousness and Experience, Cambridge, Mass., M.I.T. Press, 1996.

[13]. Place. U.T., 'Is Consciousness a Brain Process?', British Journal of Psychology, 47, 44-50, 1956.

[14]. Place. U.T., 'Materialism as a Scientific Hypothesis', Philosophical Review, 69, 101-104, 1960.

[15]. Rosenthal. D.M., 'A Theory of Consciousness'. In Block, N., Flanagan, O. and Güzeldere, G. (eds) The Nature of Consciousness, Cambridge, Mass., MIT Press, 1996. 